\title{
La crisis del modelo tradicional de regadíos del interior valenciano. El caso de Cortes de Pallás: paisajes del agua y patrimonio cultural*
}

Jorge Hermosilla Pla

Miguel Antequera Fernández

Emilio Iranzo García

Universitat de València. Departamento de Geografía

jorge.hermosilla@uv.es

miguel.antequera@uv.es

emilio.iranzo-garcía@uv.es

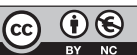

Recibido: septiembre de 2019

Aceptado: diciembre de 2019

Publicado: marzo de 2020

\section{Resumen}

Los sistemas tradicionales de regadío forman un legado que se manifiesta mediante lo que conocemos como paisaje y patrimonio del agua. En las áreas del interior valenciano se experimentan disfunciones socioeconómicas que se evidencian paisajísticamente. A partir del análisis en profundidad de un caso de estudio como es la huerta de Cortes de Pallás, en el sector septentrional del macizo del Caroig, se valora si los procesos en ella identificados explican las dinámicas de crisis de los regadíos históricos del interior. El abandono de una parte destacada de las parcelas ha sido una práctica común, aun manteniéndose su morfología y una red de acequias que sigue en funcionamiento.

Palabras clave: regadíos tradicionales; paisajes del agua; patrimonio hidráulico; medio rural en crisis

Resum. La crisi del model tradicional de regadius de l'interior valencià. El cas de Cortes de Pallars: paisatges de l'aigua i patrimoni cultural

Els sistemes tradicionals de regadiu formen un llegat que es manifesta mitjançant el que coneixem com a paisatge i patrimoni de l'aigua. A les àrees de l'interior valencià s'hi experimenten disfuncions socioeconòmiques que s'evidencien paisatgísticament. A partir de l'anàlisi en profunditat d'un cas d'estudi com és l'horta de Cortes de Pallars, en el sector septentrional del massís del Caroig, es valora si els processos que s'hi identifiquen expliquen les dinàmiques de crisi dels regadius tradicionals de l'interior. L'abandonament d'una part destacada de les parcel.les ha estat una pràctica comuna, encara que se'n mantingui la morfologia i una xarxa de sèquies que continuï en funcionament.

Paraules clau: regadius tradicionals; paisatges de l'aigua; patrimoni hidràulic; món rural en crisi

* Este artículo es resultado de la investigación realizada en el marco del proyecto europeo «Museums and Community: Concepts, Experiences, and Sustainability in Europe, Latin America and the Caribbean (EU-LAC-MUSEUMS)», financiado por el programa de investigación e innovación Horizonte 2020 de la Unión Europea en virtud del acuerdo de subvención n. 693669. 
Résumé. La crise du modèle traditionnel d'irrigation de l'intérieur valencien. Le cas de Cortes de Pallás: paysages aquatiques et patrimoine culturel

Les systèmes d'irrigation traditionnels constituent un héritage qui se manifeste à travers ce que nous appelons le patrimoine paysager et hydrologique. Dans les régions de l'intérieur valencien, il y a des dysfonctionnements socio-économiques qui se manifestent dans le paysage. L'analyse approfondie d'une étude de cas telle que celle du verger de Cortes de Pallás, dans le secteur nord du Macizo del Caroig, permet de déterminer si les processus identifiés dans celle-ci expliquent la dynamique de crise des irrigations de l'intérieur. L'abandon des pratiques agricoles a été courant, tout en maintenant la morphologie des parcelles ainsi qu'un réseau de canaux encore en activité.

Mots-clés: irrigation traditionnelle; paysages de l'eau; patrimoine hydraulique; zones rurales en crise

Abstract. Crisis of traditional irrigation systems in the Valencian inlands. A case study of Cortes de Pallás: Water landscapes and cultural heritage

Traditional irrigation systems are a legacy that is manifested through the landscape and hydraulic heritage. The inland areas of Valencia suffer socioeconomic dysfunctions manifested in the landscape. Based on an in-depth analysis of the buerta of Cortes de Pallás situated in the northern area of Macizo del Caroig, we analyze if the processes identified explain the crisis affecting these historical inland irrigation systems. Many plots have been abandoned, even though the morphology and the irrigation system is still functioning.

Keywords: traditional irrigation; water landscape; hydraulic heritage; rural environment crisis

\section{Sumario}

1. Introducción 5. Resultados. Los regadíos de Cortes de

2. Marco teórico

Pallás en la actualidad

3. Materiales y métodos

6. Discusión y conclusiones

4. Regadío y territorio en Cortes de Pallás

Referencias bibliográficas

\section{Introducción}

Los regadíos históricos forman parte del conjunto de paisajes mediterráneos característicos. Generan unidades paisajísticas de contrastado valor patrimonial y cultural que configuran una arquitectura hidráulica singular. Existen importantes diferencias entre los regadíos de las áreas litorales, situados en llanuras de inundación, y los de interior, localizados en pequeños valles fluviales y áreas montañosas. Se derivan de las formas del terreno, que condicionan el tamaño de los sistemas. Los macrosistemas predominan en las amplias llanuras costeras, mientras que los mesosistemas y los microsistemas son habituales en el interior montañoso. Las diferencias entre los sistemas de regadío de interior y de litoral se constatan en términos de jerarquía, caudal, topografía y parcelario irrigable. 
El objetivo principal de este artículo es la identificación de los factores y de los procesos que condicionan la actual crisis de los regadíos históricos del interior valenciano, en los espacios donde estos riegos han permitido configurar unos paisajes del agua valiosos. A partir del análisis en detalle de un ejemplo del interior valenciano, las huertas de Cortes de Pallás, se comprueba si el actual modelo cortesano ${ }^{1}$ puede constituir un referente de la situación de crisis de los regadíos históricos. El artículo determina las singularidades de la huerta de origen morisco de Cortes de Pallás, que complementa los rasgos de los regadíos de interior. Además, en el regadío cortesano despuntan ciertas singularidades, como son la labor del Ayuntamiento, órgano gestor del riego, que mantiene la red de acequias en funcionamiento, y la presencia de la Reserva Nacional de Caza de la Muela de Cortes, que genera considerables problemas al agricultor que están relacionados con la fauna incontrolada.

\section{Marco teórico}

En el territorio valenciano, el agua, en sus diferentes manifestaciones, es protagonista en la configuración del paisaje. A su capacidad de modelar el terreno y de condicionar las formaciones vegetales se le suma su influencia en el desarrollo de la vida humana. La necesidad de agua explica la ubicación de los asentamientos, próximos a manantiales o a cursos de agua, a partir de los cuales se han desarrollado otras actividades antrópicas, también modeladoras del paisaje. Sin embargo, en los paisajes valencianos es frecuente encontrar una presencia velada del agua. El clima mediterráneo está en la base de una disponibilidad estacionalmente limitada (Pérez, 1994; Gil y Olcina, 1997) a la que los grupos humanos han sabido sobreponerse gracias al ingenio y a la construcción de infraestructuras hidráulicas. Un espacio geográfico con agua explica el tipo de formaciones vegetales y de cultivos, así como la disposición de los mismos (Frolova, 2008). Ello da lugar a morfologías diferenciadas, a paisajes que se encuentran en la base de representaciones y a imágenes sociales muy profundas (Mata y Fernández, 2010). El manejo de las aguas a lo largo de la historia ha propiciado sustanciales cambios ambientales y una impronta cultural que se refleja en la organización territorial y social (Hermosilla e Iranzo, 2010).

Los paisajes del agua pueden ser analizados desde distintas perspectivas. Especial protagonismo ha tenido la aproximación ambiental-ecológica y la ligada a los servicios ecosistémicos que ofrecen estos paisajes (Mitsch y Gosselink, 2000; Boulton et al., 2016; Pueyo-Ros et al., 2017). No obstante, esta no es la única dimensión de estudio de los paisajes del agua. Existe toda una escuela que ha centrado su atención en las configuraciones, materiales e inmateriales, resultantes de la gestión humana del recurso hídrico: instituciones hidrosociales, aspectos tecnológicos, agronómicos, patrimoniales y sociales. Esta perspectiva de aproximación se interesa por los valores de los paisajes culturales del agua,

1. Cortesano es el gentilicio de Cortes de Pallás, por lo que cuando la palabra aparezca en el texto tendrá ese significado. 
también por sus retos y por los problemas relacionados, por un lado, con los procesos de modernización del riego en pro de un ahorro hídrico, con estrategias de fortalecimiento de su viabilidad socioeconómica, y con dinámicas de urbanización, especialmente en entornos metropolitanos (Sanchis-Ibor et al., 2015), y, por otro lado, con procesos de despoblamiento rural y abandono de la actividad agrícola de regadío. La consecuencia inmediata es el deterioro de la red de irrigación y de las estructuras patrimoniales del agua.

La dimensión cultural de los paisajes del agua nos presenta unas estructuras y unas representaciones territoriales que son el resultado del trabajo conjunto a lo largo del tiempo de la naturaleza y los seres humanos (Cruz, 2017). Son paisajes valorados por sus múltiples cualidades, y en muchos lugares constituyen un soporte identitario de la comunidad que los gestiona. En relación con esta última dimensión cultural del estudio de los paisajes del agua, cabe señalar que existe toda una corriente de investigaciones en torno a los sistemas de regadío tradicionales y sus paisajes, que se apoya en los trabajos previos de investigadores como Antonio López Gómez entre los geógrafos, Arthur Maass entre los politólogos, Miquel Barceló entre los arqueólogos y Thomas F. Glick entre los historiadores (Sanchis, Hermosilla e Iranzo, 2004). La investigación no se detuvo en sus trabajos, sino que otros investigadores han dado continuidad a esta línea. Ejemplo de ello son Helena Kirchner (1999) y Carmen Navarro (1995), que han abordado los fundamentos de la hidráulica andalusí y la captación de aguas subterráneas mediante galerías drenantes. Destaca la obra dirigida por Jorge Hermosilla (2010) Los regadios históricos españoles: Paisajes culturales, paisajes sostenibles, que supone un compendio de diversas aportaciones de investigadores de universidades españolas. También hay que remarcar los trabajos de Alfredo Morales (1992), José María Gómez Espín (2004 y 2010), Encarnación Gil Meseguer (2007) y José Antonio López (2013), que han tratado los distintos aspectos que caracterizan a los regadíos murcianos. Por lo que respecta al sudeste andaluz, destacan las aportaciones de Antonio Malpica (1997), María del Carmen Trillo (2004), José Francisco Ruiz (2013) o José Castillo (2014), para el caso de Granada; y las de Andrés Sánchez Picón (1997) y Jesús Rodríguez Vaquero (2007), para el de Almería. En el territorio valenciano destaca la Escuela Valenciana de Geografía, en la que hallamos autores como Antonio López Gómez (1990), Joan Mateu, Juan B. Marco y Joan Romero (1994), Jorge Hermosilla y Emilio Iranzo (2010 y 2014), Carles Sanchis (2001), y posteriormente la alicantina, con Antonio Gil Olcina y Alfredo Morales Gil (1992), Jorge Olcina, María Hernández y Antonio Rico Amorós (2010).

Los regadíos tradicionales constituyen un entramado cultural de gestión de los recursos hídricos y del suelo, que se manifiesta mediante las unidades paisajísticas de las huertas, las vegas y las riberas. Superando lo meramente objetivo, estos espacios se presentan como lugares repletos de historia y de significados; lugares en donde se une el pasado y el presente, y en donde se evidencian las costumbres, los modos de entender la vida y las relaciones de poder (Griñán y Trigueros, 2018). Son auténticos paisajes culturales; espacios cargados de valores, pero que por su condición de legado paisajístico marcado 
por las necesidades cambiantes de la producción, se trata de espacios de lo útil y con pocas estructuras de carácter monumental que no han gozado de la consideración que merecen. El principal desafío en la promoción de los sistemas de regadío tradicionales y sus paisajes del agua asociados es el desarrollo de nuevas oportunidades para el ecoturismo y el ocio al aire libre como motor de la sostenibilidad (Ricart et al., 2019).

En los últimos veinte años se ha renovado el interés por el análisis de los sistemas de regadío tradicionales. Un interés que va más allá de la visión agronómica, especialmente ahora, en un momento en que la agricultura tradicional experimenta una situación crítica y es cada vez más cuestionada. Así, a los trabajos previos arriba citados se incorporan bajo el enfoque paisajísticopatrimonial los trabajos de Jorge Hermosilla (2010), Rafael Mata y Santiago Fernández (2010), Rocío Silva (2008) y Pablo Giménez (2008), entre otros. Efectivamente, los paisajes hidráulicos del regadío han empezado a ser considerados desde una perspectiva patrimonial, que de algún modo enriquece sus dimensiones ecológica, histórica y geográfica. Como antes se apuntaba, ello exige análisis de sus valores y articulación de instrumentos de protección, gestión y, si es necesario, ordenación de dichos paisajes.

El estudio de los sistemas de regadío tradicionales desde una perspectiva paisajístico-patrimonial requiere de unos trabajos previos, a veces infravalorados entre la propia comunidad universitaria, de identificación, delimitación cartográfica y catalogación de acequias y artefactos que permiten su funcionamiento. La creación de un SIG con un método de caracterización y valoración de los regadíos tradicionales permite, además de contar con la representación de la red de canales y acequias y con el inventario de los elementos del patrimonio del agua, efectuar el análisis de la configuración y del significado paisajístico de los regadíos, así como el valor patrimonial del conjunto.

La organización tradicional de los paisajes irrigados se ha ido conformando en torno a tres elementos principales que han estructurado y jerarquizado todo ese territorio: los núcleos de población, los caminos y el sistema de riego (Castillo, 2014). Como señala Maciá (2016), el regadío en espacios caracterizados por la escasez hídrica ha sido el elemento fundamental para ordenar el territorio prácticamente hasta mediados del siglo xx. Tanto la dimensión espacial como la histórica tienen mucha relevancia en su configuración, ya que le confieren unas características genuinas que permiten la identificación de los distintos colectivos que lo han ido conformando, así como su distinción respecto a otros grupos sociales de hábitats diferentes. La consideración patrimonial de los regadíos tradicionales y de los paisajes asociados confirma una apertura de planteamientos. Se ha pasado del estudio del hito aislado a la valoración del conjunto, del sistema espacial y del paisaje. Se trata de un recorrido conceptual que ha permitido el reconocimiento patrimonial del legado de la agricultura (Silva, 2008).

No obstante, este patrimonio de lo funcional es un patrimonio frágil, sometido a la problemática de su dispersión y de su progresivo deterioro por desuso. Con la consolidación de sociedades de carácter urbano, donde el medio rural y sus conocimientos tradicionales se marginan, los sistemas de regadío tradicionales 
se ven seriamente amenazados por diferentes motivos. Unos ligados al éxodo rural y al abandono generalizado de una actividad agrícola incapaz de generar rentas comparables a otros sectores y con altas exigencias de dedicación. Y otros ligados a la mecanización y a la tecnificación del campo, donde la búsqueda de la optimización de las explotaciones y el eterno problema de la escasez hídrica ha instado a la sustitución del riego a manta por otros métodos a priori más eficientes. La actual y futura revitalización de los regadíos históricos mediterráneos precisa de la adopción y la adaptación de funciones y actividades que complementen a la tradicional producción de alimentos u otros bienes agrarios. La idea central de la multifuncionalidad, entendida como la dimensión social y ecológica de la actividad agraria, es que la agricultura y las áreas rurales, además de proporcionar alimentos y fibras, cumplan funciones beneficiosas para la sociedad, como la provisión de espacio y paisaje para el ocio y el turismo; la protección de la naturaleza; la creación de puestos de trabajo y la generación de ingresos en el ámbito rural, y la gestión integrada de recursos como el agua o el suelo (Ricart, 2016). Redescubrir los sistemas de regadío tradicionales, fijarlos, aunque sea a través de trabajos como este con una perspectiva paisajística y patrimonial, es una responsabilidad que hemos decidido abordar.

\section{Materiales y métodos}

La metodología aplicada para este artículo sigue las fases típicas utilizadas en el estudio de los sistemas de regadíos históricos, con la particularidad de que abordamos el análisis de la situación del riego a detalle de parcela a parcela. La metodología propuesta recoge varias fases, en las que se indican las actividades desarrolladas:

\section{Primera fase. Consulta y análisis de las fuentes de información}

Se compone de varias labores básicas:

a) La formación de un corpus teórico mediante la consulta bibliográfica y documental, completada con la búsqueda de artículos digitales.

b) La revisión de las fuentes cartográficas catastrales disponibles en el Ayuntamiento.

c) La solicitud al Servicio de Información Catastral de datos básicos sobre la propiedad en cada una de las parcelas. Se pregunta sobre el origen del propietario (si es originario de Cortes o no) y sobre su residencia actual.

\section{Segunda fase. Trabajo de campo}

En esta secuencia se implementan las siguientes tareas:

a) La identificación de los sistemas de regadío tradicionales, según su grado de funcionalidad (activo, inactivo o desaparecido). 
b) La catalogación y el inventario de los diferentes elementos hidráulicos (balsas, azudes, lavaderos, etc.). Para cada elemento se cumplimenta un modelo de ficha de inventario.

c) El análisis de cada una de las parcelas que integran la huerta de Cortes, con los siguientes datos: localización catastral (número de polígono y parcela); superficie $\left(\mathrm{m}^{2}\right)$; sistema de regadío al que pertenece; si está en producción o no; tipo de cultivo; titularidad (si el propietario es cortesano o no), y lugar de residencia.

\section{Tercera fase. Tratamiento de la información}

Para ello se ha procedido a:

a) La inclusión de los elementos hidráulicos catalogados en una base de datos.

b) Sobre estos elementos se aplica la metodología de evaluación del patrimonio hidráulico realizada por Hermosilla y Mayordomo (2016a y 2016b) para determinar su valor patrimonial. Se trata de un método cuantitativo, de tipo multicriterio, con 12 criterios y 36 variables, que permite la jerarquización de estos bienes.

c) Elaboración de una cartografía automática (SIG) donde se muestra el trazado de los sistemas de regadío y se refleja el grado de funcionalidad o de abandono de cada una de las parcelas.

\section{Cuarta fase. Presentación de la investigación a los agentes clave del territorio} (grupo focal)

Como señala Morgan (1998: 33), se trata de una metodología cualitativa, que es una técnica muy útil para obtener diferentes visiones interpretativas y para conocer la opinión y las experiencias de los principales actores, en este caso, del regadío tradicional de Cortes de Pallás. Se han realizado tres reuniones en las que participaron los técnicos municipales encargados de la gestión del sistema de regadío, varios agricultores, los propietarios de empresas de turismo y los profesores del colegio de Cortes de Pallás.

\section{Quinta fase. Análisis e interpretación de los resultados}

Reflexión sobre los resultados obtenidos y redacción de informes técnicos.

\section{Regadío y territorio en Cortes de Pallás}

\subsection{Caracterización del área de estudio}

Cortes de Pallás está situado en el interior de la provincia de Valencia, en la comarca del Valle de Ayora-Cofrentes, y tiene una extensión de $235 \mathrm{~km}^{2}$. Se localiza en el sector septentrional del macizo del Caroig, entre la sierra de 
Martés y la sierra del Ave, de orientación ibérica, al norte; la fosa de Sácaras por el oeste, y la Muela de Cortes por el sur y el este. Está atravesado de oeste a este por el río Júcar, que discurre encajado en profundos desfiladeros. Posee las características socioeconómicas comunes del interior valenciano, como son la emigración y el envejecimiento demográfico, unas actividades económicas muy limitadas y el aislamiento geográfico.

Entre los siglos x y XII, en la época de los reinos de taifas, hubo en el municipio cuatro núcleos de población con mezquita (Cortes, Otonel, Ruaya y Bujete) y cuatro castillos edificados con una estructura de taibilla formada por tierra prensada en capas encofradas, que son los de la Pileta, Ruaya, Otonel y Chirel. Los dos primeros flanquean la población de Cortes, junto a su huerta. El núcleo urbano de Cortes de Pallás está situado a $442 \mathrm{msnm}$, en la margen izquierda del Arroyo de Cortes o barranco de la Barbulla, en donde se asienta su huerta.

La huerta se gestó en época medieval, en el periodo andalusí, durante los siglos de dominación islámica. En las centurias posteriores estos sistemas tradicionales de regadío han permanecido con escasas variaciones sin que hayan existido ampliaciones ni modificaciones sustanciales en su trazado. En la actualidad se siguen conservando y se encuentran en funcionamiento los regadíos cortesanos de origen morisco.

\subsection{El agua como eje vertebrador del paisaje cortesano: el río Júcar y el barranco de San Vicente o de la Barbulla}

Los regadíos históricos de Cortes de Pallás constituyen una unidad paisajística integrada en un conjunto de espacios naturales de mayores dimensiones, como la Muela de Cortes, el Cañón del Júcar o la Muela de Albéitar. Sus huertas están integradas en un paisaje fluvial que ha sido modelado por la acción antrópica. La situación geográfica de estos regadíos ha condicionado la organización del poblamiento. Los regadíos constituyen un factor de organización y ordenación territorial, ya que su estructura rígida y de difíciles ampliaciones condicionó las estrategias de asentamiento de los núcleos de población y su posterior crecimiento demográfico (Hermosilla, 2002). La huerta de Cortes se extiende por ambas márgenes del barranco de San Vicente o de la Barbulla, merced al uso del agua de varias fuentes y algunos azudes.

La huerta posee dos estructuras defensivas de origen medieval con una localización estratégica: el castillo de la Pileta (en el extremo septentrional del regadío, que controlaba los accesos a la Muela y al núcleo urbano desde el Júcar) y el castillo de Ruaya (que vigilaba las huertas y las sendas que conectaban con el valle de Ayora).

\subsection{Identificación y características del sistema de regadio de Cortes}

El regadío histórico cortesano constituye un excelente referente de los fundamentos y principios de la arquitectura hidráulica. El regadío genera paisajes cuya morfología y dimensiones dependen del origen y del volumen de las aguas, de la orografía 
y de la disposición del parcelario. Los espacios irrigados son complejos, al ser el resultado de un diseño previo que exige comprender el territorio. El área por donde discurre el agua está mediatizada por la pendiente y condicionada por el principio de la gravedad. En este proceso de nivelación aparecen una serie de funciones ligadas a la gestión hídrica, como son las de captación, transporte, distribución, acumulación y uso. Estos sistemas son un factor de creación de unidades paisajísticas.

Los riegos de Cortes son unos regadíos de montaña adaptados a un medio difícil y a los desniveles existentes mediante un intenso abancalamiento del terreno. Se componen de parcelas alargadas, estrechas y escalonadas, acondicionadas a las sinuosidades del barranco de San Vicente o Arroyo de Cortes y a las curvas de nivel. Este parcelario abancalado está delimitado y afianzado mediante hileras de almeces (Celtis australis), lo que evita su erosión. Este árbol está integrado en la cultura cortesana, porque ha dado lugar a una actividad artesanal en la comarca, que lo utiliza como materia prima para elaboración de aperos agrícolas, bastones o toneles.

Los regadíos tradicionales de Cortes tienen su origen en acuíferos de la Muela de Cortes, por la profunda incisión del Arroyo de Cortes. El más elevado es el manantial de San Vicente o de la Barbulla, que aprovecha una intercalación de margas en la base de dolomías del Cenomaniense y del Coniaciense medio. Las inferiores, como la fuente del Jesús, de Chano, del Corbinet, de las Escalericas o del Chapole, surgen de las intercalaciones impermeables en los materiales calcáreos y detríticos del Cenomaniense inferior y del Albiense. Por la izquierda derivan las acequias de la Barbulla, la Solana y el Lugar. Por la derecha se sitúan las acequias del Jesús, la Acequia Alta y su brazal del Trance, el Agua de Enmedio y la acequia de los Huertos. En la tabla 1 se indican los

Tabla 1. Sistemas de riego tradicionales en la huerta de Cortes de Pallás

\begin{tabular}{|c|c|c|c|}
\hline Sistema & Origen* & Longitud $(\mathrm{m})^{\star \star}$ & * Partidas de riego \\
\hline $\begin{array}{l}\text { Acequia } \\
\text { de la Barbulla }\end{array}$ & Manantial de San Vicente (I) & 1.900 & La Barbulla, La Culebra \\
\hline $\begin{array}{l}\text { Acequia } \\
\text { del Jesús }\end{array}$ & Manantial en el Arroyo de Cortes (D) & 1.050 & Llano del Jesús \\
\hline $\begin{array}{l}\text { Acequia } \\
\text { de la Solana }\end{array}$ & Manantial de la Solana y azud (I) & 1.725 & La Barbulla, Rincón de la Iglesia, Ruaya \\
\hline Acequia Alta & Fuente del Chano (D) & 2.481 & Acequia Alta, Reguero Fuentes, Padul \\
\hline $\begin{array}{l}\text { Acequia Agua } \\
\text { de Enmedio }\end{array}$ & Manantial y azud de las Escalericas (D) & 1.245 & $\begin{array}{l}\text { Chapole, Agua de Enmedio, Acequilla, } \\
\text { Reguero Fuentes }\end{array}$ \\
\hline $\begin{array}{l}\text { Acequia } \\
\text { del Lugar }\end{array}$ & $\begin{array}{l}\text { Azud y manantial de las Escalericas } \\
\text { (D pero riego en I) }\end{array}$ & 930 & Chapole, El Tollo, El Muladar \\
\hline $\begin{array}{l}\text { Acequia } \\
\text { de los Huertos }\end{array}$ & Fuente del Chapole (D) & 1.042 & $\begin{array}{l}\text { Chapole, Agua de Enmedio, Reguero } \\
\text { Fuentes, La Montañica, La Pileta }\end{array}$ \\
\hline
\end{tabular}

* I: margen izquierda; D: margen derecha.

** La longitud está referida a la acequia principal, sin contar sus derivaciones.

Fuente: elaboración propia. 
sistemas de riego según el orden en el que están ubicados en el barranco. La red de acequias está interconectada entre sí, de manera que se aprovechan las aguas sobrantes del canal que circula a una cota topográfica superior. En consecuencia, cuando un sistema finaliza su trazado, el caudal remanente lo recibe la acequia que está situada inmediatamente por debajo, o derrama al barranco para que pueda ser captado aguas abajo por mediación de otro azud. Se trata, pues, de un aprovechamiento integral del agua, sin pérdidas en los recursos hídricos disponibles.

La superficie regable de los regadíos cortesanos alcanza las 60 hectáreas, aunque en la actualidad existan numerosas parcelas sin cultivar. Según la clasificación establecida por Hermosilla et al. (2009: 1501) sobre los rangos de tamaño de los sistemas hidráulicos de riego, Cortes pertenece a los sistemas menores y, dentro de los mismos, a las huertas de pequeña escala (50-250 hectáreas). Los sistemas de riego de Cortes de Pallás poseen una morfología en peine, pues disponen de una pequeña red paralela al eje y modestos riegos secundarios.

\section{Resultados. Los regadíos de Cortes de Pallás en la actualidad}

El Ayuntamiento de Cortes de Pallás es el responsable de la gestión de los sistemas de riego que configuran la huerta cercana a su núcleo urbano. Desarrolla tareas como la limpieza y la reparación de la red de acequias principales y de las balsas comunitarias. Estos riegos se conservan en unas condiciones óptimas debido a la permanente intervención del consistorio, ya que las acequias madre siguen estando en funcionamiento en la actualidad, pese a que en los últimos años el cultivo se haya abandonado en numerosas parcelas. De hecho, de las 60 hectáreas que ocupa el perímetro irrigado de las huertas de Cortes solo permanecen cultivadas 17 hectáreas, lo que equivale al $28 \%$. Se conserva el riego por gravedad, conocido coloquialmente mediante la expresión «a manta», aunque se han identificado algunas parcelas que han instalado el riego localizado. El sistema de aterrazamientos, tan característico del paisaje mediterráneo del interior valenciano, conserva su estructura original, por lo que la morfología parcelaria permanece intacta, y con ello el paisaje, pues no se aprecian cambios notables.

Los elementos hidráulicos se encuentran activos, lo que contribuye a conservar el conjunto de los sistemas de irrigación. La aplicación de la metodología de evaluación del patrimonio de tipo cuantitativo y multicriterio de Hermosilla y Mayordomo (2016a y 2016b) permite la catalogación y la valoración de la calidad patrimonial de once elementos hidráulicos en Cortes de Pallás (tabla 2). Se estructura en el uso de doce criterios de valoración divididos en tres categorías o conjuntos de valores (intrínsecos, patrimoniales y potenciales o de viabilidad). Cada criterio se desglosa en tres variables, por lo que el sistema se compone de 36 indicadores. Se otorga el valor 1 si se cumple la cualidad, y en caso contrario, el valor 0 , sin ninguna ponderación. El sumatorio de los 36 indicadores nos da la puntuación total de cada elemento. El resultado obtenido alcanza una puntuación global de 7,5 puntos en una escala decimal, lo que representa una valo- 
Tabla 2. Evaluación patrimonial de los elementos hidráulicos catalogados

\begin{tabular}{lc}
\hline Elemento & Puntuación* \\
\hline Balsa de la Barbulla & 8,1 \\
Balsa de la Solana & 8,1 \\
Balsa Grande & 8,9 \\
Azud de la Solana & 6,4 \\
Balsa de Jesús & 7,5 \\
Balsa de Ferrer o del Henchidor & 7,8 \\
Azud de la Acequia del Lugar & 6,7 \\
Balsa del Lavadero & 8,1 \\
Lavadero Municipal de Cortes de Pallás & 6,9 \\
Balsa de la Montañica & 7,2 \\
Balsa Nueva o de la Acequia Alta & 7,2 \\
\hline
\end{tabular}

* Escala decimal.

Fuente: elaboración propia.

ración patrimonial media-alta. Los bienes mejor valorados son la Balsa Grande (8,9 puntos) y las balsas de la Barbulla, de la Solana y del Lavadero (8,1 puntos).

Como se refleja en la tabla 3, solo el $25 \%$ de las parcelas de rústica integradas en los sistemas de riego en torno a Cortes permanecen cultivadas. Esta proporción es fruto del deterioro y del abandono que padecen estos regadíos. Las acequias con un mayor porcentaje de parcelas cultivadas son las del Agua de Enmedio y la Acequia Alta (en especial en su derivación de la acequia del Trance), a causa de la adecuada accesibilidad y cercanía al núcleo urbano. En las acequias de la Barbulla y de la Solana las parcelas que aún están en producción se localizan preferentemente junto al camino que une la carretera de la Muela con el manantial de San Vicente. El tipo de producciones más habituales en la huerta de Cortes son frutales, hortalizas y olivos en regadío.

Tabla 3. Situación del parcelario de rústica en los sistemas de regadío de Cortes de Pallás

\begin{tabular}{lcccc}
\hline Sistema & $\begin{array}{c}\text { Parcelas } \\
\text { cultivadas }\end{array}$ & $\begin{array}{c}\text { Parcelas sin } \\
\text { cultivo }\end{array}$ & N. $^{\circ}$ parcelas & $\begin{array}{c}\text { \% parcelas } \\
\text { cultivadas }^{-}\end{array}$ \\
\hline Acequia de la Barbulla & 17 & 64 & 81 & 21 \\
Acequia del Jesús & 1 & 27 & 28 & 3,6 \\
Acequia de la Solana & 24 & 80 & 104 & 23,1 \\
Acequia Alta & 70 & 162 & 232 & 30,2 \\
Acequia Agua de Enmedio & 27 & 39 & 66 & 40,9 \\
Acequia del Lugar* & 0 & 15 & 15 & 0 \\
Acequia de los Huertos* & 6 & 46 & 52 & 11,5 \\
TOTAL & 145 & 433 & 578 & 25,1 \\
\hline
\end{tabular}

* Algunas se sitúan en la zona urbana, por lo que no se han podido contabilizar, al estar censadas como polígonos catastrales urbanos.

Fuente: elaboración propia. 
Tabla 4. Titularidad de las parcelas de rústica de los sistemas de regadío de Cortes de Pallás

\begin{tabular}{lccccc}
\hline Sistema & $\begin{array}{c}\text { Propietario } \\
\text { de Cortes }\end{array}$ & $\begin{array}{c}\text { Propietario de } \\
\text { fuera de Cortes }\end{array}$ & Otros & Desc. & N..$^{\circ}$ parcelas \\
\hline Acequia de la Barbulla & 73 & 6 & 2 & 0 & 81 \\
Acequia del Jesús & 25 & 1 & 0 & 2 & 28 \\
Acequia de la Solana & 91 & 6 & 7 & 0 & 104 \\
Acequia Alta & 208 & 16 & 3 & 5 & 232 \\
Acequia del Agua de Enmedio & 63 & 1 & 0 & 2 & 66 \\
Acequia del Lugar & 10 & 1 & 2 & 2 & 15 \\
Acequia de los Huertos & 41 & 4 & 6 & 1 & 52 \\
TOTAL & 511 & 35 & 20 & 12 & 578 \\
\hline
\end{tabular}

Fuente: elaboración propia a partir de los datos facilitados por el Ayuntamiento de Cortes de Pallás.

La procedencia de los titulares de las parcelas de huerta cortesanas, por sistema de regadío, se indican en la tabla 4. Muestra si los propietarios son naturales de Cortes o son foráneos. El 88,4\% de las parcelas de regadío son propiedad de naturales de Cortes, debido en gran medida al aislamiento geográfico de este municipio. La acequia que dispone de un mayor porcentaje de propietarios cortesanos es la del Agua de Enmedio, con el 95,4\%, y coincide con una de las áreas donde permanecen en producción un mayor número de parcelas. En el extremo opuesto, las parcelas con un menor porcentaje de propietarios cortesanos son la acequia de los Huertos (el 78,8\%) y la acequia del Lugar (el 66,6\%), que son los sistemas ubicados junto al núcleo urbano de Cortes.

La figura 1 muestra el trazado de la red de acequias de Cortes y la localización de sus elementos hidráulicos, además de señalar si cada parcela aún se cultiva o si ha sido abandonada. La tabla 5 recoge la composición de la propiedad del parcelario del regadío cortesano para cada uno de los sistemas

Tabla 5. Lugar de residencia de los propietarios de parcelas de regadío tradicional en Cortes de Pallás

\begin{tabular}{|c|c|c|c|c|c|}
\hline Sistema & $\begin{array}{l}\text { Residentes } \\
\text { en Cortes }\end{array}$ & $\begin{array}{c}\text { No residentes } \\
\text { en Cortes }\end{array}$ & $\begin{array}{c}\text { Fallecidos } \\
\text { recientemente }\end{array}$ & Organismos ${ }^{\star \star}$ & N. ${ }^{\circ}$ parcelas \\
\hline Acequia de la Barbulla & 22 & 52 & 3 & 0 & 81 \\
\hline Acequia del Jesús & 11 & 15 & 0 & 0 & 28 \\
\hline Acequia de la Solana & 25 & 68 & 4 & 7 & 104 \\
\hline Acequia Alta & 62 & 151 & 11 & 3 & 232 \\
\hline Acequia Agua de Enmedio & 12 & 49 & 3 & 0 & 66 \\
\hline Acequia del Lugar & 4 & 6 & 1 & 2 & 15 \\
\hline Acequia de los Huertos & 16 & 26 & 3 & 6 & 52 \\
\hline TOTAL & 152 & 367 & 25 & 18 & $578^{\star}$ \\
\hline
\end{tabular}

* Se desconoce el dato de quince de los propietarios.

** Iberdrola o Administración pública.

Fuente: elaboración propia a partir de los datos facilitados por el Ayuntamiento de Cortes de Pallás. 
Figura 1. Mapa del sistema de riego tradicional de Cortes de Pallás

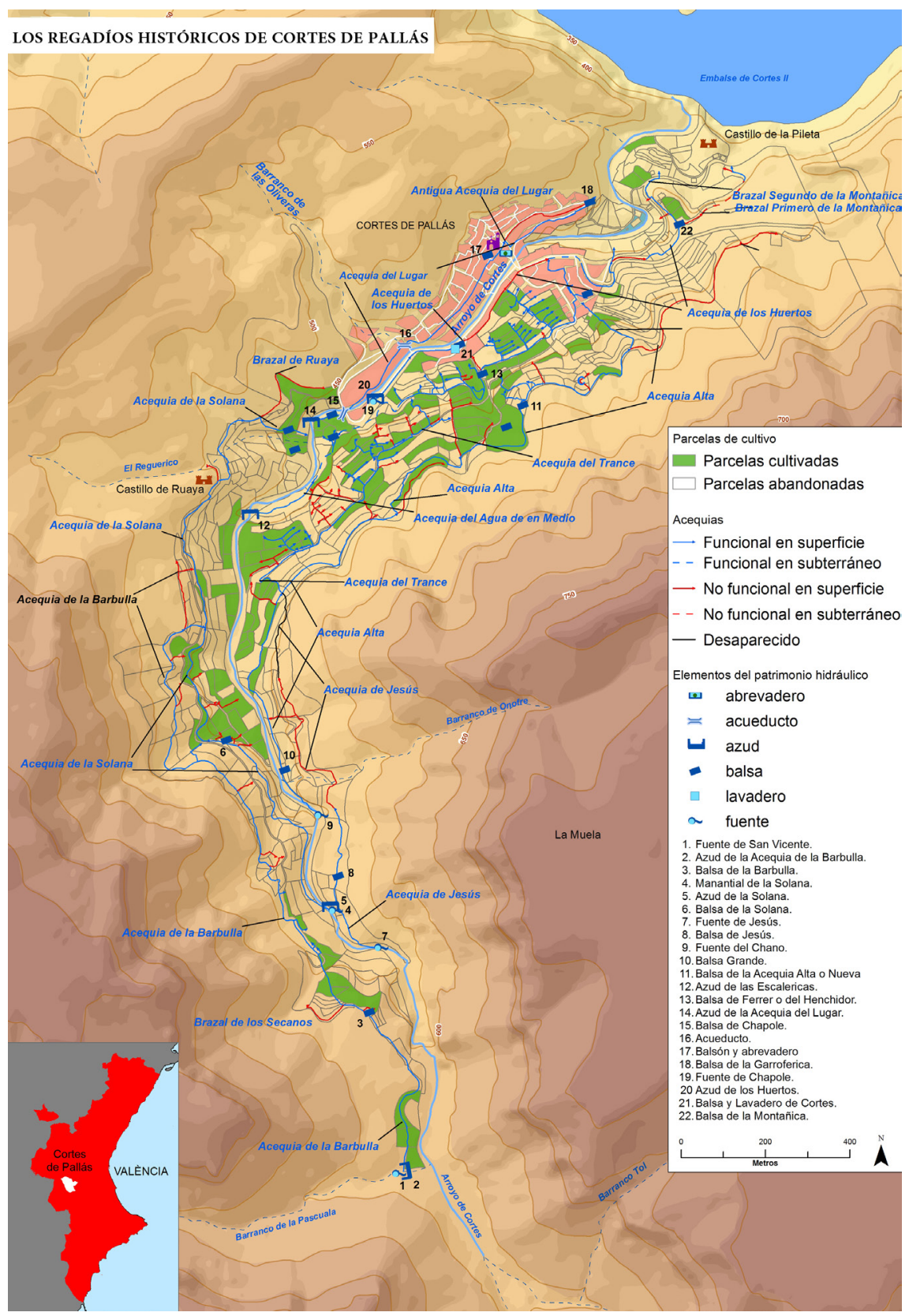

Fuente: elaboración propia. 
de regadío. El 26,3\% de los propietarios residen en Cortes de Pallás, y además la totalidad son originarios del municipio. El 63,5\% de los propietarios de las parcelas no residen en Cortes de Pallás. Llama la atención el elevado porcentaje de propietarios que no residen en Cortes, ya que supone el 57,4\%. No existe ningún propietario que no sea natural de Cortes y resida en el municipio.

Existen varios procesos territoriales que condicionan el regadío tradicional de Cortes de Pallás:

a) El núcleo urbano ha tenido una expansión desde mediados de la década de 1970 en terrenos no urbanizados. El núcleo urbano original, situado a la orilla izquierda, también se ha ampliado. Parte de la huerta tradicional se solapa con el casco urbano, y parte de las acequias del Lugar o de los Huertos han quedado soterradas.

b) En el espacio de la huerta se han detectado diversas construcciones ilegales fuera del núcleo urbano, lo que genera un impacto visual negativo.

c) El cultivo del almez, tan destacado antaño, se ha abandonado, aunque se siguen conservando bastantes ejemplares en los bordes de las parcelas abancaladas. Su repoblación permitiría apuntalar y consolidar los bancales y asegurar la estructura tradicional del parcelario.

d) Los agricultores cortesanos perciben de forma negativa la incidencia de los animales de la Reserva Nacional de Caza Muela de Cortes en los cultivos, por las afecciones a estructuras y cultivos.

\section{Discusión y conclusiones}

La huerta de origen andalusí de Cortes de Pallás constituye un referente de patrimonio paisajístico y medioambiental. Este espacio alberga unos sistemas hidráulicos caracterizados por la sostenibilidad, que han permanecido inalterados durante siglos y que en la actualidad mantienen al menos su morfología y sus elementos. El regadío cortesano también es un arquetipo de lo que ha acontecido en otras áreas del interior valenciano, caracterizadas por el abandono de parcelas de cultivo, por la despoblación y por la falta de relevo en el sector agrícola. Sin embargo, la huerta de Cortes se mantiene en un buen estado de conservación, debido a algunas singularidades. El papel del Ayuntamiento de Cortes es decisivo, ya que, al no existir comunidad de regantes, es quien gestiona el mantenimiento de la red de acequias y de sus elementos hidráulicos asociados. Los sistemas conservan intacta su morfología, porque tanto el parcelario como los elementos no han variado su estructura a lo largo de los años. Los elementos asociados al sistema se conservan activos y en buen estado, a excepción de alguno desaparecido, como el Balsón y su abrevadero.

La figura 2 refleja los factores y los procesos que han incidido en la crisis de los regadíos históricos y nos permite integrar los procesos generales con los resultados específicos del caso de estudio. En el regadío tradicional de Cortes de Pallás se hallan referencias de los procesos que caracterizan los regadíos históricos del interior valenciano, definidos por el contraste entre la crisis del 
Figura 2. Factores y procesos de la crisis del regadío histórico de Cortes de Pallás

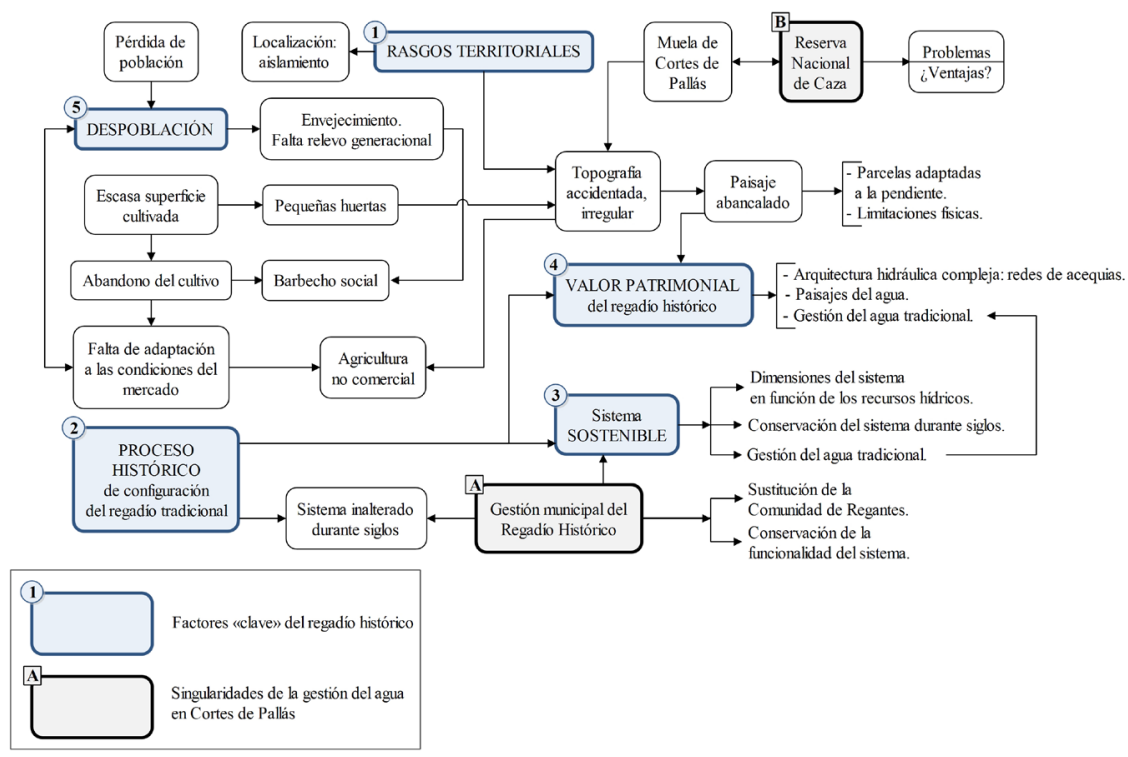

Fuente: elaboración propia.

modelo agrícola y su significado patrimonial. Las huertas de Cortes sufren el mismo retroceso que otros municipios del interior. El éxodo rural afecta a las áreas de interior, ya que se abandona progresivamente la economía basada en la agricultura, de manera que en la actualidad tiene una función testimonial por su falta de rentabilidad. La agricultura se percibe como un sector económico inestable, ya que se ha producido un descenso de los rendimientos agrícolas al reducirse los beneficios. En ocasiones genera incluso pérdidas. Se produce un envejecimiento de los agricultores, al no existir el relevo generacional necesario, porque los jóvenes emigran y los que permanecen no quieren dedicarse a esta actividad. Se ha extendido la práctica de la agricultura a tiempo parcial (ATP), en esta ocasión realizada por jubilados, y por lo tanto como afición y para abastecimiento de consumo particular. En ocasiones incluso se observa una actividad vinculada al fin de semana. En cualquier caso, se trata de una agricultura de subsistencia, de autoconsumo, que no se ha adaptado a los parámetros de la agricultura comercial. La atomización de la propiedad y el minifundismo impiden que la mayoría de estas parcelas puedan ser mecanizadas. La estructura parcelaria se encuentra muy fragmentada.

En Cortes de Pallás se han detectado una serie de procesos singulares que condicionan la actual situación de crisis del regadío tradicional. El aislamiento geográfico del municipio tiene su origen en unos relieves muy accidentados y restrictivos para el ejercicio de actividades económicas, una circunstancia que 
supone dificultades para las comunicaciones, lo que acentúa su confinamiento. Ello tiene su reflejo en el porcentaje de propietarios que son originarios de Cortes, que alcanza el $88 \%$. De la misma manera, es singular la función del Ayuntamiento en el mantenimiento de la red de acequias y de elementos hidráulicos. El consistorio posee un potencial económico notable por la instalación de empresas hidroeléctricas en su término, lo que repercute positivamente en que los sistemas sigan funcionales. La Reserva Nacional de Caza de la Muela de Cortes es uno de los principales problemas que afectan al regadío cortesano. La fauna formada por cabras hispánicas, jabalíes, muflones, etc. genera el deterioro de las producciones agrícolas y las estructuras parcelarias. Los agricultores muestran su descontento y su desánimo e intentan que esta situación se pueda solucionar, estableciendo medidas correctoras que tendrían que realizarse de acuerdo con los responsables de la Reserva Nacional. En la actualidad la Reserva se extiende hasta el embalse y abarca el Arroyo de Cortes, donde se asienta el regadío tradicional, y el núcleo urbano cortesano. Tanto los responsables municipales como los agricultores solicitan que la Reserva Nacional se retranquee y su límite se sitúe en la Muela de Cortes, para evitar así los efectos perjudiciales sobre bancales y cultivos.

Como se ha puesto de manifiesto en este trabajo, el agua es un agente modelador del paisaje. El manejo del agua que las comunidades han realizado a lo largo de la historia ha dado lugar a paisajes singulares de alto valor ecológico, histórico y simbólico, como son los paisajes del regadío. Sin embargo, los paisajes del regadío del interior valenciano están seriamente amenazados por una diversidad de factores. Se ven afectados por una crisis estructural generada por el abandono de las tierras de cultivo, como resultado de procesos de crisis demográfica y de escasa rentabilidad de las explotaciones. En consecuencia, se produce una desestructuración de los paisajes del regadío de interior. Así acontece en Cortes de Pallás, si bien con matices. Mientras que en buena parte de esos regadíos de interior los sistemas de riego han dejado de estar activos como consecuencia del abandono de las prácticas agrícolas, en Cortes la arquitectura hidráulica permanece en uso y en buen estado de conservación, fruto del mantenimiento que efectúa el Ayuntamiento. Las acequias madre no se han deteriorado por la falta de gestión, tal y como sucede en otras huertas locales de zonas de montaña afectadas por la despoblación y el envejecimiento.

El regadío tradicional de la huerta de Cortes de Pallás es un paisaje identificador de la cultura del agua en las tierras valencianas de interior. Constituye un referente y un ejemplo de sistema de riego en ladera aterrazada, organizado a partir de la captación de agua de manantiales y barrancos. No obstante, el porcentaje de abandono de las parcelas es muy elevado, ya que únicamente se explota una cuarta parte de las mismas. Para los habitantes de Cortes y las instituciones públicas locales, sus huertas tradicionales tienen una consideración social contrastada, ya que las valoran de forma muy positiva. Sin embargo, existe al mismo tiempo una apatía, tanto institucional como del colectivo de agricultores, cuando se intentan solucionar los problemas que afectan a este 
espacio. Actualmente este paisaje experimenta cambios. El abandono de una parte destacada del parcelario o la sustitución de cultivos hortícolas por otros más adecuados en la práctica de una agricultura a tiempo parcial hace que, aun manteniéndose la morfología del parcelario y la red de acequias, la dinámica y la estructura visual del paisaje sea diferente.

A pesar de todo, las particularidades que tiene Cortes de Pallás nos permite pensar que la organización básica de un paisaje minifundista de regadío se preserva. Algo similar sucede en otros lugares, como en el valle del Reconque-Cautabán (Hermosilla, 2002) y en la Vega del Magro en Utiel-Requena (Hermosilla, 2005), en los cuales el parcelario y el funcionamiento del sistema de riego se mantienen, así como las instituciones que lo gestionan, pero han cambiado el tipo de cultivo y por tanto la estructura visual del paisaje.

\section{Referencias bibliográficas}

Boulton, Andrew J.; Eкebom, Jan y Gíslason, Gísli már (2016). «Integrating ecosystem services into conservation strategies for freshwater and marine habitats: A review». Aquatic Conservation: Marine and Freshwater Ecosystems, 26 (5), 963-985.

Castillo Ruiz, José (2014). «Cultivando el agua. Valoración y protección de los sistemas históricos de riego: El caso de la Vega de Granada». En: Lozano, María del Mar (coord.). Patrimonio cultural vinculado con el agua: Paisaje, urbanismo, arte, ingeniería y turismo. Mérida: Editora Regional de Extremadura, 301-320.

CRUZ, Linarejos (2017). «El agua como elemento generador de paisajes culturales: Una visión desde el Plan Nacional de Paisaje Cultural». En: Lozano, María del Mar y Méndez, Vicente (eds.). Paisajes culturales del agua. Cáceres: Servicio de Publicaciones de la Universidad de Extremadura.

Frolova, Marina (2008). «El estudio de los paisajes del agua en una cuenca vertiente: Propuesta metodológica». Revista de Estudios Regionales, 83, 21-47.

Gil Meseguer, Encarnación (coord.) (2007). Sistemas locales de recursos propios de agua en la Región de Murcia: Minados y galerías. Murcia: Universidad de Murcia. Usos del Agua en el Territorio, 4, 190 p.

Gil Olcina, Antonio y Morales Gil, Alfredo (coord.) (1992). Hitos históricos de los regadios españoles. Madrid: Ministerio de Agricultura, Alimentación y Medio Ambiente, $415 \mathrm{p}$.

Gil Olcina, Antonio y Olcina Cantos, Jorge (1997). Climatología general. Barcelona: Ariel, 579 p.

Giménez Font, Pablo (2008). Las transformaciones del paisaje valenciano en el siglo XVIII: Una perspectiva geográfica. Valencia: Institució Alfons el Magnànim, 460 p.

Gómez Espín, José María (2004). Aprovechamiento integral del agua en la Rambla de Nogalte (Puerto Lumbreras-Murcia). Murcia: Universidad de Murcia. Usos del Agua en el Territorio, 1, $190 \mathrm{p}$.

Gómez Espín, José María; López Fernández, José Antonio y Montaner Salas, Elena (coord.) (2010). Modernización de regadios: Sostenibilidad social y económica. La singularidad de los regadios del trasvase Tajo-Segura. Murcia: Universidad de Murcia. Usos del Agua en el Territorio, 6, 439 p.

Griñán, María y Trigueros, Juan Carlos (2018). «Patrimonio y paisaje cultural del agua en el Valle de Ricote (Murcia)». e-rph-Revista Electrónica de Patrimonio Histórico, 22, 5-36. 
Hermosilla, Jorge (dir.) (2002). El patrimonio del agua en el valle de Ayora-Cofrentes. Generalitat Valenciana. Conselleria de Cultura, Educació i Esport. Regadíos Históricos Valencianos. Recuperem Patrimoni, 1, 302 p.

- (2005). El regadio histórico en la comarca de Requena-Utiel: Geografía y Patrimonio. Valencia: Generalitat Valenciana. Conselleria de Cultura, Educació i Esport. Regadíos Históricos Valencianos. Recuperem Patrimoni, 4, 231 p.

- (2010). Los regadios históricos españoles: Paisajes culturales, paisajes sostenibles. Madrid: Ministerio de Medio Ambiente y Medio Rural y Marino. Gestión Tradicional del Agua, Patrimonio Cultural y Sostenibilidad, 3, 608 p.

Hermosilla, Jorge; Estrela, Teodoro y PeÑa, Martín (2009). «Los regadíos históricos españoles». En: Geografía, territorio y paisaje: El estado de la cuestión. Actas del XXI Congreso de Geógrafos Españoles. Ciudad Real, 27-29 de octubre de 2009, 1499-1512.

Hermosilla, Jorge e Iranzo, Emilio (2010). «Censo de hidráulica tradicional en el Mediterráneo peninsular». Áreas: Revista Internacional de Ciencias Sociales, 29, 73-89.

- (2014). «Claves geográficas para la interpretación del patrimonio hidráulico mediterráneo: A propósito de los regadíos históricos valencianos». Boletín de la Asociación de Geógrafos Españoles, 66, 49-66.

Hermosilla, Jorge y Mayordomo, Sandra (2016a). "A Methodological System for Hydraulic Heritage Assessment: A management Tool». Water Science and Technology: Water Supply, 17 (3), 879-888. <https://doi.org/10.2166/ws.2016.186>

- (2016b). Sistema metodológico de evaluación del patrimonio hidráulico. Valencia: Tirant lo Blanch.

Kirchner, Helena (1999). «Observaciones a propósito de la hidráulica andalusí». En: Morilla Critz, José; Gómez Pantoja, Joaquín L. y Cressier, Patrice (eds.). Impactos exteriores sobre el mundo rural mediterráneo: Del imperio romano a nuestros días. Madrid: Ministerio de Agricultura, Pesca y Alimentación, 139-161.

López Fernández, José Antonio (2013). «Aprovechamiento del agua en el municipio de Mula: Región de Murcia». Revista Papeles de Geografía, 57-58, 145-159.

López Gómez, Antonio (1990). Estudios sobre regadios valencianos. Valencia: Universitat de València, $177 \mathrm{p}$.

Maciá Navarro, Francisco (2016). Agua y ordenación del territorio en la primera mitad del siglo XX en la comarca de l'Alacantí. Universidad de Alicante. Tesis doctoral.

Malpica, Antonio (1997). "Arqueología hidráulica y poblamiento medieval en la Vega de Granada». Fundamentos de Antropología, 6, 208-231.

Mata Olmo, Rafael y Fernández Muñoz, Santiago (2010). «Paisajes y patrimonios culturales del agua». Scripta Nova, 14 (337), 1-24.

Mateu, Joan; Marco, Juan B. y Romero, Joan (1994). Regadios históricos valencianos: Propuestas de rehabilitación. Valencia: Conselleria d'Agricultura i Pesca. Servei d'Estudis Agraris i Comunitaris, 158 p.

Mitsch, William J. y Gosselink, James G. (2000). "The value of wetlands: Importance of scale and landscape setting». Ecological Economical, 35-1, 25-33.

Morales Gil, Alfredo (1992). «Origen de los regadíos españoles: Estado actual de una vieja polémica». En: Gil Olcina, Antonio y Morales Gil, Alfredo (coord.). Hitos históricos de los regadíos españoles. Madrid: Ministerio de Agricultura, Alimentación y Medio Ambiente, 15-47.

Morgan, David L. (1998a). The Focus Group Guidebook. Thousand Oaks, Londres y Nueva Delhi: SAGE. <http://dx.doi.org/10.4135/9781483328164> 
Navarro, Carmen (1995). «El tamaño de los sistemas hidráulicos de origen andalusí: La documentación escrita y la arqueología hidráulica». En: Agricultura y regadio en Al-Andalus: II Coloquio Historia y Medio Físico. Almería: Instituto de Estudios Almerienses de la Diputación de Almería y Grupo de Investigación «Toponimia, Historia y Arqueología del Reino de Granada», 177-190.

Olcina, Jorge; Hernández, María y Rico Amorós, Antonio M. (2010). «Los regadíos del Vinalopó, Alicante». En: Hermosilla, Jorge (dir.) (2010). Los regadios históricos españoles: Paisajes culturales, paisajes sostenibles. Madrid: Ministerio de Medio Ambiente y Medio Rural y Marino, 285-306. Gestión Tradicional del Agua, Patrimonio Cultural y Sostenibilidad, 3.

Pérez Cueva, Alejandro (1994). Atlas Climático de la Comunidad Valenciana. Valencia: Generalitat Valenciana. Conselleria de Obras Públicas, Urbanismo y Transportes.

Pueyo-Ros, Josep; Fraguell, Rosa M. y Ribas, Anna (2017). «Propuesta metodológica para valorar la calidad escénica de los paisajes del agua y su potencial como recurso turístico». Investigaciones Geográficas, 68, 79-94. Alicante: Universidad de Alicante. Instituto Interuniversitario de Geografía.

RicART, Sandra (2016). «Entre la multifuncionalitat i la legitimitat social del regadiu: Un estat de la qüestió». Documents d'Anàlisi Geogràfica, 62 (1), 161-181. <https://doi.org/10.5565/rev/dag.273>

Ricart, Sandra; Ribas, Anna; Pavón, David; Gabarda-Mallorquí, Ariadna y Roset, Dolors (2019). "Promoting historical irrigation canals as natural and cultural heritage in mass-tourism destinations». Journal of Cultural Heritage Management and Sustainable Development, 9 (4), 520-536. <https://doi.org/10.1108/JCHMSD-12-2017-0089>

Rodríguez-Vaquero, Jesús E. (2007). «Clasificación e ilustración de los paisajes hidráulicos de la Cuenca del río Andarax y los campos de Níjar (Almería)». Nimbus, 19-20, 215-232.

Ruiz, José Francisco (2013). «Sistema de riego en la Vega de Granada: El mantenimiento de un paisaje agrario a partir de los repartos de agua de riego». e-rph: Revista Electrónica de Patrimonio Histórico, 12, 3-30.

Sánchez-Picón, Andrés (1997). «Los regadíos de la Andalucía árida (siglos XIX y xx): Expansión, bloqueo y transformación». Áreas, 17, 109-128.

Sanchis Ibor, Carles (2001). Regadiu i canvi ambiental a l'Albufera de València. Valencia: Universitat de València. Departament de Geografia.

Sanchis Ibor, Carles; Hermosilla Pla, Jorge e Iranzo García, Emilio (2004). «Entorn al patrimoni hidràulic del regadiu històric valencià». Saitabi: Revista de la Facultat de Geografia i Història, 54, 223-234.

Sanchis-Ibor, Carles; Macian-Sorribes, Héctor; García Mollá, Marta y PulidoVelázQuez, Manuel A. (2015). «Effects of drip irrigation on water consumption at basin scale (Mijares river, Spain)». En: 26th Euro-Mediterranean regional conference and workshops on "innovate to improve irrigation performances», Montpellier, France, 12-15.

Silva, Rocío (2008). "Hacia una valoración patrimonial de la agricultura». Scripta Nova: Revista Electrónica de Geografía y Ciencias Sociales, XII (275).

Trillo SAn José, María del Carmen (2004). Agua, tierra y hombres en Al-Ándalus: La dimensión agrícola del mundo nazarí. Granada: Grupo de Investigación «Toponimia, Historia y Arqueología del Reino de Granada». 